\title{
DESIGN AND DEVELOPMENT OF AN ACADEMIC ADVISING SYSTEM FOR IMPROVING RETENTION AND GRADUATION
}

\author{
Kamal Hingorani, Alabama State University, khingorani@alasu.edu \\ Nasrin Askari-Danesh, Alabama State University, ndanesh@alasu.edu
}

\begin{abstract}
Graduation and retention is a major concern for all universities. Faculty members, in spite of their teaching, research and service loads, are being asked to pay more attention to students' advisement. The quality of faculty advisement is also being monitored at the highest level. Although most universities have implement student advisement systems through ERP systems, these advisement systems do not provide the desired support to faculty for advisement. This is more evident where a university has implemented an out-of-the-box solution from a vendor without major customization. This paper describes an Advisement System designed to mitigate the issues of an outof-the-box implementation at a southeastern university to help improve retention and graduation.
\end{abstract}

Keywords: Information Technology (IT), Advisement, Retention, Database, Web-based systems, Role of Faculty.

\section{INTRODUCTION}

Faculty academic advising has a significant impact on a student's academic success. A recent report has found that over $75 \%$ of private institutions in the U.S. have instituted a policy of mandatory one-on-one faculty advising with over $84 \%$ of these institutions reporting that this strategy is effective in improving retention and graduation [1]. A recent doctoral dissertation found that the more a student and his or her advisor discussed personal and schoolrelated issues, career options, college policies, academic deadlines, and study skills and tips, the more likely it was that the student positively developed and had a higher level of satisfaction with college [6].

Historically, many colleges have received state funding based on how many full-time equivalent students are enrolled at the beginning of the semester. Twenty-five states-Arizona, Arkansas, Florida, Illinois, Indiana, Kansas, Louisiana, Maine, Massachusetts, Michigan, Minnesota, Mississippi, Missouri, New Mexico, Nevada, North Carolina, North Dakota, Ohio, Oklahoma, Pennsylvania, South Dakota, Tennessee, Texas, Utah and Washingtonhave a funding formula in place that allocates some amount of funding based on performance indicators such as course completion, time to degree, transfer rates, the number of degrees awarded, or the number of low-income and minority graduates [7].

Retention and graduation rate is becoming the mantra in many universities across the U.S. Table-1 below summarizes the retention and graduation rates for different types of universities [5].

\begin{tabular}{|l|c|c|}
\hline \multicolumn{3}{|c|}{ Table-1 } \\
\hline \multicolumn{1}{|c|}{ University Selectivity Type } & $\begin{array}{c}\text { First to Second Year } \\
\text { Retention Rates }\end{array}$ & $\begin{array}{c}6 \text {-Year } \\
\text { Graduation Rates }\end{array}$ \\
\hline Highly Selective (Top 10\% HS; ACT 25-30) & $90 \%$ & $86 \%$ \\
\hline Selective (Top 25\% HS; ACT 21-26) & 84 & $60.5 \%$ \\
\hline Traditional Selective (Top 50\% HS; ACT 18-24) & $70.6 \%$ & $43.7 \%$ \\
\hline Liberal Selective (Bottom 50\%; ACT 17-22) & $59.1 \%$ & $38.5 \%$ \\
\hline Open (No \%; ACT 16-21) & $57.4 \%$ & $36.8 \%$ \\
\hline All Master's Granting Public & $72.2 \%$ & $44.4 \%$ \\
\hline
\end{tabular}

Retention and Graduation is a major issue in all universities except the highly selective universities. 


\section{CURRENT STATE OF FACULTY-LED ADVISEMENT}

Tier-1 universities in the U.S. have dedicated professional staff for advisement. The role of faculty in such institution is best summarized by the following quote of Dr. Cecilia Gaposchkin, Assistant Dean of the Faculty for pre-major advising [2]:

The advising system consists of a host of different resources and people that students will access at different points during their academic careers. The system is decentralized by design. The enormous range of available opportunities means that no single person has mastery of all the possible paths or options. Thus, students won't have a single advisor throughout their entire time at Dartmouth, though at any given time they may rely on the advice of an individual person (faculty member, administrator, peer advisor) to a greater or lesser extent. As a student moves through Dartmouth, the nature of the advice a student needs changes dramatically, and with these changes so do the appropriate advice-networks. Academic advising works best when a student appreciates his or her own role in understanding the questions they have and taking the initiative to seek the advice they need.

In smaller universities faculty have to carry the full-load of advisement. Some faculty do not take this role seriously. One reason is that advising has very rarely been fully integrated into the faculty assessment and reward system, i.e., teacher/scholar/service tenure process, the dilemma of either no assessment/reward system or parallel advising systems of assessment and recognition is one reason for faculty not taking this role very seriously [4].

Most universities have instituted online ERP systems with built-in advisement systems. In some of the smaller universities, these systems have been implemented out-of-the-box. Customization of these systems has been slow as they need consultants and are expensive to implement. Motivating faculty to use the system that is not very intuitive (a system that forces them to navigate multiple screens for basic information) has proved to be difficult. Such implementations have required faculty to keep paper-records, thus making the whole process laborious, tedious and difficult to monitor.

The three major student systems software vendors are Oracle's PeopleSoft, SAP Campus Management, and SunGard's Banner and most universities in the U.S. use one of these three systems. Our campus has adopted the PeopleSoft system. Contrary to "PeopleSoft philosophy" and marketing claims, PeopleSoft Campus Solutions (CS) is about $80 \%$ complete, as delivered. In other words, there is a lot missing that has to be customized [3].

This paper presents a web-based system developed by the Computer Information Systems department at a southeastern university in the U.S. The system was designed with two main objectives, one was to provide a onepage view of the students' demographics and academic progress for faculty advisement and the second was to monitor the effectiveness and the quality of faculty advisement by the college administration. This system has been successfully adopted by the entire college of business administration and has met both the objectives set forth.

\section{PEOPLESOFT'S CAMPUS SOLUTION}

PeopleSoft Campus Solutions is an expensive solution. Universities such as Stanford, Arizona State and Penn have made the PeopleSoft implementation in their campus a great success through major customizations. Smaller schools, who do not have the technical and financial resources, have implemented the out-of-the-box solution. Such institutions have had limited success with their PeopleSoft implementation. Many units at such universities still use their own spreadsheets for processes that should be handled by the system. Training of users and customization to make the system easier to use are two major issues with the system.

Although PeopleSoft Campus Solution provides a student advisement module, the system is not easy to use. It is a windows-based system that uses a number of navigation links. A faculty advisor is presented a list of the advisees on a page. Each student is hyperlinked to a new page that displays some of the academic information of the student. Although all courses attempted by the student are listed with the semester and the advisor can sort the list on semester, the sorting is not chronological. The fall semesters are listed first, followed by spring and then by summer semesters. This should be an easy fix, because the data for semester is coded as 2141 for spring, 2146 for summer, and 2148 for fall. 


\section{Issues in Information Systems \\ Volume 15, Issue II, pp. 344-349, 2014}

Most students in smaller universities receive funds through federal student Aid (Title IV). Students receiving funds under Title IV must complete their degrees within 150 percent of the published program length as measured in credits or forfeit federal aid. On the PeopleSoft system, Title IV satisfactory academic progress is not available for faculty advisement. Monitoring satisfactory academic progress (SAP) is important both for retention and graduation. The PeopleSoft system has "what-if" capabilities and enhanced usability that have not been implemented at our university. The system has a degree audit on a different navigation link which gives out a print-out of seven pages. This audit is useful for clearing students for graduation but using the degree audit for advising a student every semester is cumbersome. .

This paper reports on a very simple advisement system developed in-house that provides all data required by an advisor on one single page and also allows the advisor to enter the gist of the advisement session with the student. The system was developed using ASP.Net with the data stored in an Access database. The database tables were designed to conform with the database tables on the PeopleSoft system so that the application could work on the Oracle database whenever the MIS could provide us read access to the underlying database. Data is downloaded and imported to the Access tables through PeopleSoft queries.

\section{USERS' REQUIREMENTS}

The new advisement system had the following objectives:

1. Provide a one-page view of the whole advisement process.

a. Use the existing data structure adopted by the PeopleSoft system.

b. Show the degree-audit on the advisement page.

c. Allow the user to plan for three semesters in advance.

d. Allow the user to record the gist of all advisement sessions.

e. Allow the advisor to email from the page.

f. Allow the advisor to view the records from the RFID attendance system.

2. Provide a control system that would allow the administration to monitor the quality of advisement and the retention and graduation rates.

\section{OVERALL DESCRIPTION OF THE SYSTEM}

The one-page advisement page is shown in Figure-1.

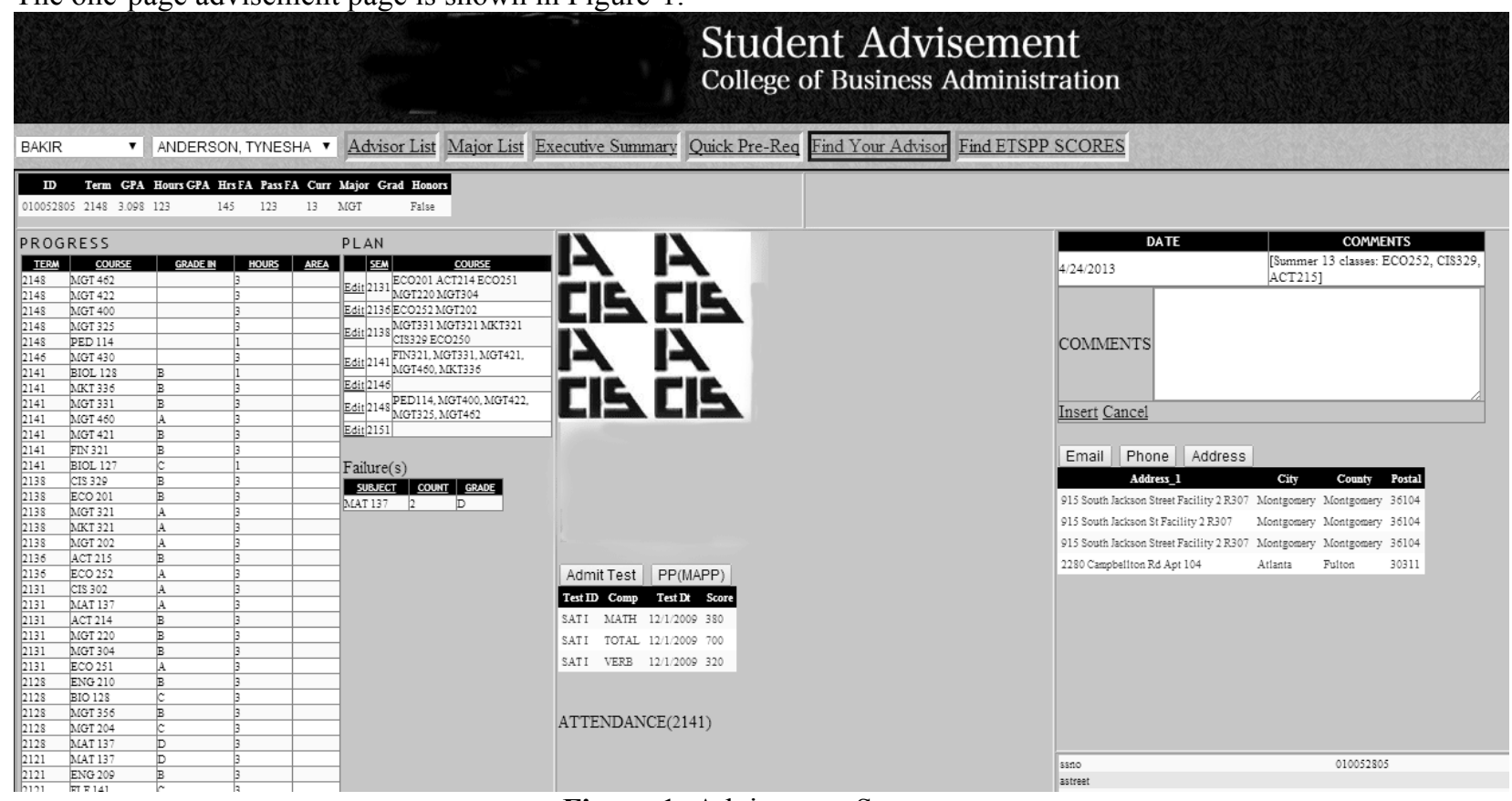

Figure 1: Advisement System 


\section{Issues in Information Systems \\ Volume 15, Issue II, pp. 344-349, 2014}

The advisor is presented with a drop-down with a list of all advisors. On selection of an advisor, all advisees of that advisor are displayed on a second drop-down list. The advisor selects the advisee and all information necessary for advisement is presented on the page. The page has 7 modules as described in Table- 2 below:

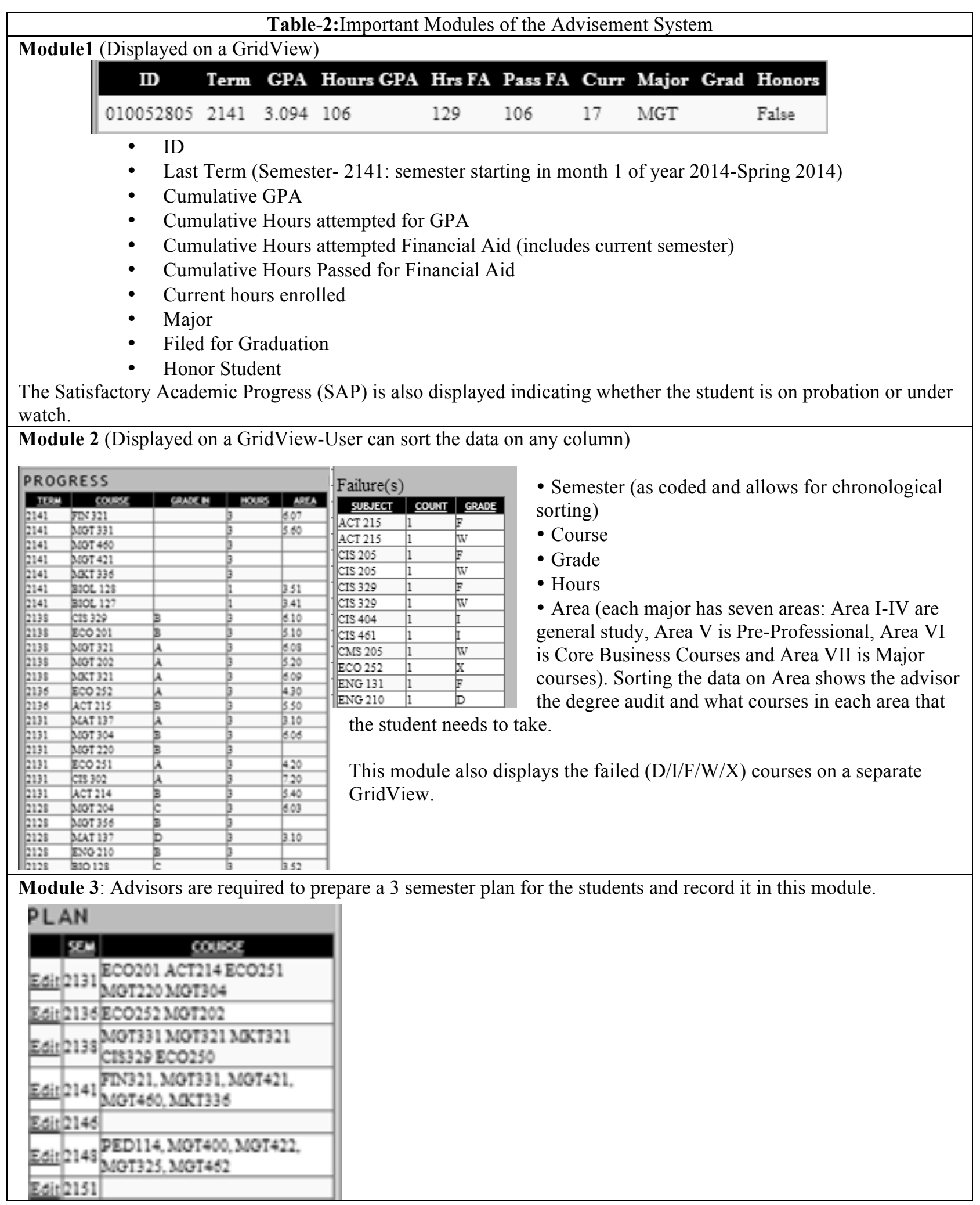


Module 4: Advisors can see the email/phone/address of their advisees on a GridView. They can also email their

\begin{tabular}{|c|c|c|c|c|c|}
\hline Email & Phone & Address & & & \\
\hline \multicolumn{3}{|c|}{ Address_1 } & City & County & Postal \\
\hline \multicolumn{3}{|c|}{915 South Jackson Street Facility 2 R307 } & Montgomery & & 36104 \\
\hline \multicolumn{3}{|c|}{915 South Jackson St Facility 2 R307 } & Montgonery & USA & 36104 \\
\hline \multicolumn{3}{|c|}{915 South Jackson Street Facility 2 R307 } & Montgomery & & 36104 \\
\hline \multicolumn{3}{|c|}{2280 Campbellton Rd Apt 104} & Atlanta & & 30311 \\
\hline
\end{tabular}
advisees from this page.

Module 5: The College has implemented a RFID based attendance system. The number of classes attended by each

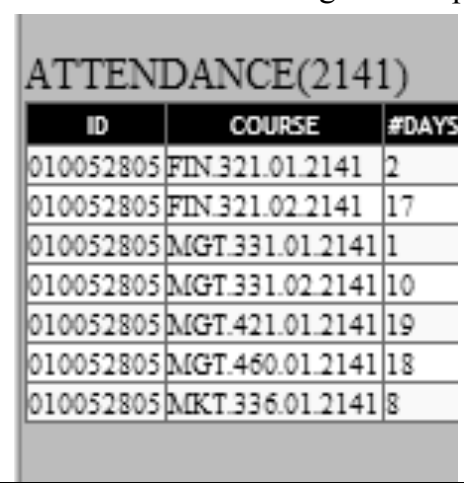
student for each of the classes is shown on a GridView. This helps in counseling students who miss classes and make poor grades.

Module 6: The gist of all advisements can be recorded in the database. A simple interface is provided for data entry.

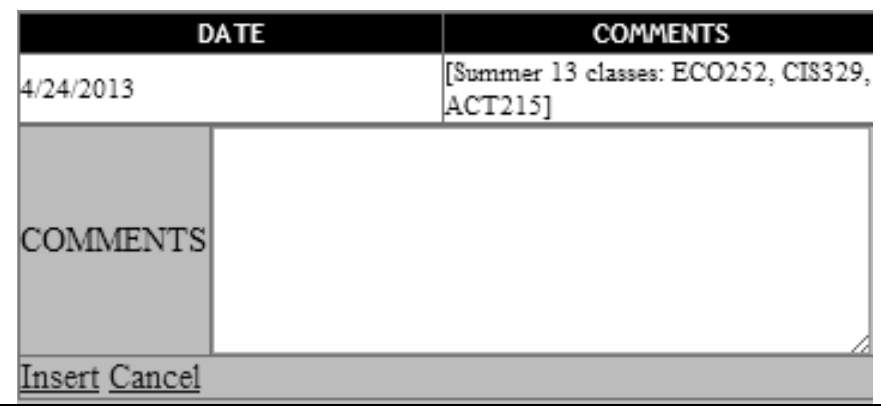

Module 7: Reports (Generated using Crystal Reports)

1. Advise list per department

2. Advise list per advisor

3. Advisement report for a selected period through an Executive Information System.

On request of the faculty, an additional module for checking the pre-requisites for courses was also added to the system. This was an easy implementation since the data was already available in the database. The page for this application displays all the courses on a drop-down list and on selection of a course, all students that have not met the pre-requisites are displayed along with the deficient courses.

\section{DESIGN AND IMPLEMENTATION ISSUES}

The system was designed using ASP.Net. The database was implemented in Access. The table structure matched the structure of the database used by the PeopleSoft system, making future migration to live Oracle tables easier. Reports were designed using Crystal Reports and integrated with the ASP.Net application. Security, through user authentication, was built into the system. The data is updated daily during the advisement period and during the $1^{\text {st }}$ week of the semester. Thereafter it is updated every 2 -weeks or whenever deemed necessary. We have a pending request with the MIS to provide read-access to the Oracle database, but they have been reluctant to do that. A simple data structure is shown in Figure-2 below. 


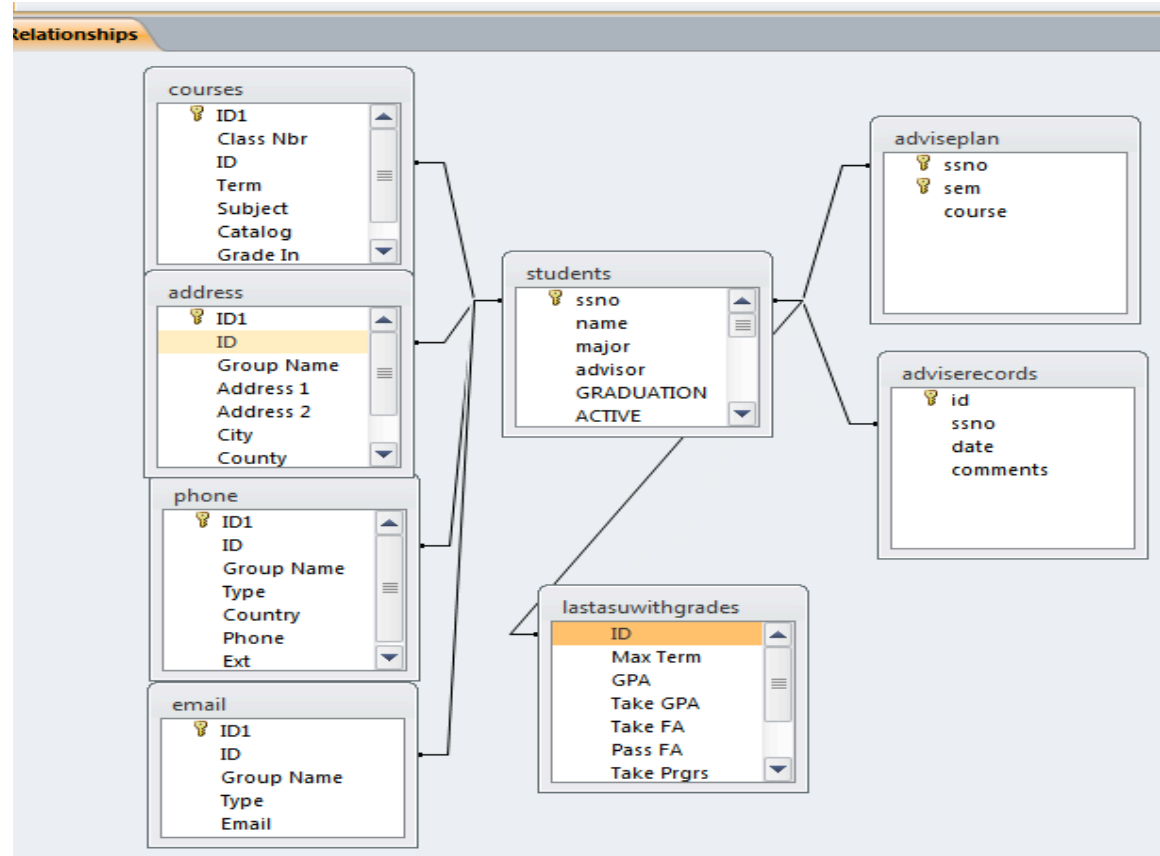

Figure 2: Data Structure for the Advisement System

\section{CONCLUSIONS}

Given that "the quality of academic advising is the single most powerful predictor of satisfaction with the campus environment," it is disturbing to note that college student's rank advising so unfavorably [8]. Student satisfaction with faculty advising is very polarized, tending to rate this kind of interaction very favorably or very poorly [8]. One reason is that the faculty are neither trained nor assessed for the quality of their advisement. This paper describes an attempt to closely involve faculty with student advisement through a web-based advisement system. The system has worked remarkably well with high-level of satisfaction reported both by the students and the faculty.

\section{REFERENCES}

1. 2013 Student Retention and College Completion Practices Report. (n.d.). Noel-Levitz Higher Education Consulting. Retrieved May 13, 2014, from https://www.noellevitz.com/papers-research-highereducation/2013/2013-student-retention-and-college-completion-practices-report

2. Academic Advising Resources. (n.d.). Academic Advising Resources. Retrieved May 15, 2014, from http://www.dartmouth.edu/ upperde/advising/

3. Google Groups. (n.d.). Google Groups. Retrieved May 13, 2014, from https://groups.google.com/forum/\#!topic/fisica teorica/Uup8K1T17B8

4. McGillin, V., Ortgies-Young, T.S., \& Kem, L. (2010, September). Faculty advisor assessment and reward: A hot topic for our institutions. Academic Advising Today, 33(3). Retrieved May 13, 2014, from http://www.nacada.ksu.edu/Resources/Academic-Advising-Today/View-Articles/Faculty-AdvisorAssessment-and-Reward-A-Hot-Topic-for-Our-Institutions.aspx

5. National Collegiate Retention and Persistence to Degree Rates. (n.d.). Retrieved May 15, 2014, from http://www.act.org/research/policymakers/pdf/retain 2013.pdf

6. Parget, K. (2011, December 1). The Effects of Academic Advising on College Student Development in Higher Education. . Retrieved May 13, 2014, from http://digitalcommons.unl.edu/cgi/viewcontent.cgi?article $=1083 \&$ context $=$ cehsedaddiss

7. Performance-Based Funding for Higher Education. (n.d.). Performance-Based Funding for Higher Education. Retrieved May 15, 2014, from http://www.ncsl.org/research/education/performancefunding.aspx

8. The Pennsylvania State University Division of Undergraduate Studies. (n.d.). The Mentor. Retrieved July 12, 2014, from http://dus.psu.edu/mentor/2013/08/comparing-satisfaction-faculty-professional-advisers 